Julio- Diciembre 2017

\title{
Migración y Sus Efectos en el Desarrollo Regional
}

\author{
Dr. Félix Mauro Higuera Sánchez \\ fhiguera@navojoa.uson.mx \\ (045) 6424280681 \\ Dra. Celia Guadalupe Torres Ayala \\ cgtorres@navojoa.uson.mx \\ (045) 6428535394 \\ Lic. Patricia Pacheco Borbón \\ Patty_pacheco_569@hotmail.com
}

\begin{abstract}
:
Entendiendo que la migración se ha dado a través de la historia y desarrollo del ser humano, y más se ha acentuado debido muy diversos factores, como faltas de oportunidades en sus países de origen, problemas políticos, desastres naturales, estrategias comerciales y de producción en el caso de las empresas, siendo entre otras de las principales causas y que repercuten en nuestras economías que se han internacionalizado a lo cual conlleva la existencia que se rompan las barreras migratorias, se realiza un análisis teórico, cuyo objetivo es el estudio de este fenómeno que ha cobrado actualidad y sus repercusiones que deriva de una investigación en proceso, es una descripción, análisis y su evolución. Usando como metodología el estudio de la dogmática teórica jurídica aplicable de tipo descriptivo y analítico, para lo cual se recurre a las técnicas de investigación documental con fuentes doctrinarias y normativas. Como conclusión: es de suma importancia el análisis de la evolución de los efectos que esto puede traer sobre el desarrollo económico, político y cultural, por nombrar algunos, por ser multifacético la influencia sobre la sociedad
\end{abstract}


Julio- Diciembre 2017

Año 10

Revista de Investigación

Núm. 26

Académica sin Frontera

ISSN: 2007-8870

\section{http://revistainvestigacionacademicasinfrontera.com}

Palabras claves: Migración, Desarrollo Humano, Efectos

\section{Introducción}

Podemos considerar que es multifactorial las causas de la migración, la más común es por cuestiones económicas ya que muchos individuos migran ya sea de una región a otra o a otras naciones en busca de mayor percepción económica y un mejor nivel de vida, este fenómeno ocurre principalmente en naciones menos desarrollados a otras con mejor desarrollo y en la mayoría de los casos, estas personas se encuentran de manera irregular en el país de destino

Otros factores son situaciones particulares del país de origen de la persona migrante, ya sea por persecución política, étnica religiosa o la guerra, o por políticas de inestabilidad de su propio estado.

También se está asociado a profesiones en específico o empleos, como en el caso de constructoras o mineras, organizaciones no gubernamentales internacionales, de investigación científica, o como parte de su desenvolvimiento profesional.

Podemos considerar que las migraciones internacionales se producen cuando convergen las siguientes causas de acuerdo con (GOZÁLVEZ PÉREZ, 2000): 1) excedentes relativos de población en los países de partida, originados tanto por los procesos de transición demográfica que producen fuertes incrementos naturales de población a resultas de un descenso más temprano de la mortalidad que de la natalidad, como por devenir insuficiente el sistema económico que debía sustentar a esa población en crecimiento rápido; 2) atractivos económicos relativos en los países de destino; 3) funcionamiento de las redes migratorias, que actúan sobre los emigrantes tanto en la etapa pre migratoria como en la pos migratoria; 


\section{http://revistainvestigacionacademicasinfrontera.com}

los vínculos relacionados con el trabajo, los familiares y los socioculturales, son determinantes; 4) facilidad relativa para el transporte o desplazamiento.

Lo cual es importante analizar, estudiar sus causas y efectos ya que entendiendo esto serviría para construir políticas públicas a largo plazo principalmente en derechos humanos concreta afín de evitar la migración y promover el desarrollo económico de toda región.

\section{Desarrollo}

\section{Antecedentes de la migración}

De acuerdo a diversos autores la migración es una de las fuerzas históricas que han moldeado al mundo, consideran que la migración siempre ha sido parte de la conducta humana, siendo esta un fenómeno natural tan antiguo como la historia de la humanidad, el ser humano siempre ha migrado ya sea localmente o en grades distancias.

Según los autores (Alonso \& Otero, 2016) Los desplazamientos y cambios de residencia de grupos humanos de unas zonas a otras han sido constantes desde la remota prehistoria. Nomadismos, invasiones, peregrinajes, expediciones comerciales y colonizaciones han construido el mundo que hoy conocemos.

La primera migración fue la que sacó de su patria originaria en África a nuestros ancestros en diversas oleadas para expandirse por el mundo. ¿Qué les empujó a emprender tan colosal viaje? Probablemente aquellas primeras avanzadillas de Homo ergaster, acuciadas por el hambre y por un aumento de la población, aprovecharon una bonanza climática hace 1,7 millones de años para entrar en Asia y colonizar nuevos territorios. Después, sucesivas oleadas de homínidos cada vez más evolucionados siguieron avanzando en busca de mejores 


\section{http://revistainvestigacionacademicasinfrontera.com}

oportunidades de caza, hasta alcanzar Europa, donde la presencia humana (Homo antecessor) está fechada hace unos 700.000 años.

Una vez asegurada la ocupación de África y Eurasia, ya en tiempos del hombre moderno (Homo sapiens sapiens), tuvo lugar el poblamiento del continente americano, uno de los episodios del pasado que más controversia suscita. La tesis más aceptada por los antropólogos es la de que los primeros americanos eran cazadores asiáticos que llegaron desde las tundras siberianas hace unos 15.000 años a través del estrecho de Bering, probablemente persiguiendo grandes mamíferos.

Esto fue posible porque durante los periodos de glaciación, Siberia y Alaska formaban un solo territorio emergido por el que se podía pasar andando de un continente a otro. Las otras teorías sobre la penetración humana en América, como la de la travesía del Pacífico por australianos o polinesios, o la navegación del Atlántico por europeos, resultan menos verosímiles. Alrededor de 8000 a. de C., la revolución agrícola del Neolítico permitió que algunas comunidades se hicieran sedentarias en Asia Menor y la cuenca del Mediterráneo, foco de las primeras civilizaciones, pero el impulso viajero no menguó.

Por esas fechas, sucesivas partidas de pueblos con lenguas similares agrupados bajo la denominación de indoeuropeos empiezan a poblar Europa. Su origen es incierto: pudieron venir de la India, de las estepas siberianas, del Cáucaso o incluso de Dinamarca. En todo caso, su paulatina conversión de cazadores- recolectores en agricultores elevó la demografía y provocó nuevos movimientos de población. Hacia 2200 a. de C., estos pueblos se desplegaron por el continente; las migraciones hacia el sur (Creta, Chipre, Tesalia) dieron origen al mundo grecolatino, mientras que en el centro y oeste proliferaron las tribus celtas y germánicas. 


\section{http://revistainvestigacionacademicasinfrontera.com}

Durante el primer milenio a. de C., los griegos y fenicios navegaron por todo el Mediterráneo, creando asentamientos en el norte de África, Italia y España. Por esa época, el desarrollo de las primeras ciudades -polis- provocó también un movimiento migratorio del campo a la ciudad que luego se ha dado en todas las civilizaciones.

Tras el Imperio romano y las invasiones bárbaras -que se detallan en la parte siguiente de este documento-, los vikingos tomaron el testigo viajero y con sus drakkars navegaron mares y ríos en numerosas expediciones de exploración y conquista. Invadieron Irlanda y Gran Bretaña, arribaron a las costas de Canadá, atacaron varias localidades gallegas y penetraron por el Guadalquivir hasta Sevilla.

A partir del Descubrimiento del Nuevo Mundo en 1492, comienza una era de grandes movimientos migratorios. Los avances geográficos y técnicos permitieron el traslado controlado de personas a las nuevas colonias ultramarinas, bajo la dirección de los gobiernos o a cargo de compañías mercantiles. Las naciones europeas -España, Portugal, Francia, Inglaterra, Holanda, Bélgica, Alemania- se expandieron por África, Asia y, sobre todo, América. Si Europa, por su alta densidad demográfica, ha sido una cantera de emigrantes, América es la eterna tierra de promisión. La inmensidad de su territorio, repleto de riquezas naturales, y la bajísima tasa de población, eran un reclamo irresistible para los colonizadores, que emprendieron una nueva vida lejos de las guerras que sacudían Europa.

Como contrapartida, su llegada fue devastadora para los pueblos de América Central y del Sur (mayas, aztecas, incas...), cuyas culturas fueron aplastadas y su población mermada por las enfermedades introducidas por españoles y portugueses. En el Norte la colonización francesa y anglosajona también fue fatal para los indígenas, que vieron trastocados sus modos de vida y acabaron exterminados o confinados a reservas. 


\section{http://revistainvestigacionacademicasinfrontera.com}

En todo caso, mientras las colonias se mantuvieron dependientes de las metrópolis, los traslados presentaron cifras reducidas. Se calcula en 100.000 el número de españoles inmigrados a la América hispana durante el primer siglo colonial (1492-1600). Sin embargo, a partir de la emancipación de los Estados americanos a inicios del siglo XIX, hasta la primera mitad del XX, se produjo el mayor trasvase de población de la Historia.

\section{Migración su definición}

A través de la historia la movilización de personas siempre ha sido una constante, pero en las últimas décadas se ha incrementado en forma exponencial, a lo cual podemos considerar el tener que definir este fenómeno y sus consecuencias.

Según ( Ruiz Garcia, 2002) "Por migración entendemos los desplazamientos de personas que tienen como intención un cambio de residencia desde un lugar de origen a otro de destino, atravesando algún límite geográfico que generalmente es una división políticoadministrativa"

(Abu-Warda, 2008) citando a L. Varlez, en un artículo sobre migraciones internacionales, daba la siguiente definición: "emigrante o inmigrante, es toda persona que abandona su país para establecerse en el extranjero, bien sea de una manera permanente o bien de una forma duradera, con objeto de satisfacer las necesidades que juzga esenciales"

Asimismo, ( Borisovna Biriukova , 2002) en su libro Vivir un espacio. Movilidad geográfica de la población, menciona que "la decisión de migrar es el resultado de un cálculo racional en el cual cada individuo compara los costos de la migración con sus recompensas.

(González, 2014) citando a Bogue nos dice Una migración es un cambio de residencia que envuelve un cambio completo y un reajuste de las afiliaciones comunitarias del individuo 


\section{http://revistainvestigacionacademicasinfrontera.com}

(Diccionario demografico multilingüe, 2017) define Se da el nombre de migración o movimiento migratorio, al desplazamiento, con traslado de residencia de los individuos, desde un lugar de origen a un lugar de destino o llegada y que implica atravesar los límites de una división geográfica.

\section{Tipos de migración}

(Micolta León, 2005) citando a Tizón García Son varios los criterios escogidos por los estudiosos, para establecer las diversas tipologías de migraciones. teniendo en cuenta aspectos como el tiempo, el modo de vida, las necesidades y demandas profesionales, la edad y el grado de libertad, establece la siguiente clasificación:

Según el tiempo:

a) Estacionales. Son las de aquellos individuos, generalmente trabajadores, que se trasladan para recolecciones u otros trabajos y que sólo se realizan en determinadas temporadas del año.

b) Temporales reiteradas. Aquellas en donde a las personas se les renueva su contrato de trabajo, a medida

que la empresa contratante va acometiendo nuevas tareas, hasta que se finalizan las mismas.

c) De varios años. Es la expectativa más frecuente entre los emigrantes modernos. Se emigra generalmente con la fantasía, a menudo irreal, de que solamente se va a estar unos años fuera del país de origen.

En muchos casos ello no es así y la emigración se convierte, en definitiva.

d) Indefinidas. Se parte del lugar de origen con la idea de no volver a éste, salvo en vacaciones o en viajes ocasionales. 


\section{http://revistainvestigacionacademicasinfrontera.com}

Según el modo de vida:

Tiene que ver con las preferencias de un modo de vida de acuerdo a las actividades que realicen las personas en consonancia con su proceso vital.

Según las demandas y necesidades profesionales:

a) Buscando un status profesional estable. Es el caso de los trabajadores del campo que se incorporan a la industria.

b) Exigencia de la actividad profesional. Tal es el caso de los militares, funcionarios, diplomáticos, etc.

c) Búsqueda de un desarrollo superior. Aquí se engloban las migraciones de los intelectuales, que buscan nuevos horizontes formativos y/o profesionales fuera de sus fronteras.

Según la edad:

a) Infantil. Los niños suelen cambiar de país acompañando a sus padres, generalmente al mismo tiempo o después que éstos.

b) De adultos. Son los que lideran el proceso a partir de sus criterios y necesidades, incluyendo en estas aquellas que les atañen como responsables del cuidado, atención y manutención de otros.

c) De ancianos. Los ancianos pueden verse forzados a abandonar su pueblo por diversos motivos: porque va quedando deshabitado, para buscar disfrute y mejor calidad de vida en otros lugares después de la jubilación o porque sus hijos ya han emigrado con anterioridad y quedan solos.

Según el grado de libertad: 


\section{http://revistainvestigacionacademicasinfrontera.com}

a) Voluntarias. Hoy este tipo de migración se observa especialmente en aquellas personas cuyo móvil y motivación principal es de tipo económico.

b) Forzosas. Dentro de éstas se consideran:

- Los esclavos. En épocas de colonización fueron llevados grandes contingentes de seres humanos para ser explotados por los colonizadores. Esta práctica perduró durante largos años.

- Los deportados o desterrados. Son aquellos a los que se les obliga a dejar su país o región porque se les quita su tierra. Aunque sufren todos los avatares de la emigración y generalmente descienden en su status social, muchas veces pueden ser ayudados por otros compatriotas o por organizaciones sociales o políticas.

- Los refugiados. Aquellos que han de abandonar su país porque de lo contrario peligran su medio inmediato de vida o incluso su vida misma. Al igual que los anteriores, suelen tener más dificultades de asentamiento en el país receptor ya que a menudo hacen el cambio precipitadamente.

También se realiza una distinción de acuerdo al límite geográfico:

- Internas

- Externas o internacionales

En cuanto a su duración pueden ser transitorias o definitivas; de acuerdo a la decisión de los sujetos pueden ser espontaneas, dirigidas o forzadas; Por causas se derivan las ecológicas políticas o económicas.

Considerándose que la migración espontanea es donde el individuo decide voluntariamente realizar la migración sin verse forzado a realizarlo, a diferencia de la dirigida donde se dan 


\section{http://revistainvestigacionacademicasinfrontera.com}

por ofrecimientos de trabajo en el caso de contratación de mano de obra extranjera, y en el caso de migraciones forzadas se ubican los desplazados por las guerras, exiliados, repatriados etc.

En cuanto a las ecológicas son aquellas en las cuales son motivadas por catástrofes naturales o situaciones que complican la vida de las personas como son los terremotos tsunamis, catástrofes provocados por el ser humano como exposición de radioactividad.

Las económicas son las más comunes frente al atractivo de una mejora de vida del individuo y su familia, las políticas tienen una connotación en cual puede ser por intolerancia política, religiosas, étnicas, raciales entre otras.

\section{Efectos positivos y negativos que inciden en el desarrollo de las regiones por causas de la migración}

Entre los beneficios positivos inmediatos sobre la migración ya sea nacional o internacional son las remesas que se envían por parte de los migrantes a sus lugares de origen ya que impulsan la economía de sus propias regiones y que pueden ser significativas en la economía regional o nacional, considerando que en 2010 fue el principal receptor de remesas en América latina, lo cual mejoro directamente el poder adquisitivo principalmente en las poblaciones rurales.

De lo cual se ha demostrado que con el otorgamiento de las remesas ha contribuido a la formación de micro empresas, dando un impulso al desarrollo y más variedad en actividades productivas contribuyendo al mejoramiento de su calidad de vida.

Siendo tan significativos que tanto sociedades civiles como gubernamentales han impulsado o generado políticas públicas que con base a las remesas den impulso al desarrollo económico 


\section{http://revistainvestigacionacademicasinfrontera.com}

de las comunidades de donde son originarios y fomentar principalmente la participación de proyectos productivos y generación de infra estructura.

Asimismo, un a cambio en la diversificación de la cultura tanto de la el país o región receptora como también del migrante cuando vuelve a su región de origen, considerando se en benéfico la diversificación cultural del mismo.

En cuanto a los efectos negativos se pueden destacar como:

Una disminución de mano de obra del país emisor y una ganancia de la región receptora, de los cual se traduciría en perdida de mano de obra y de capital humano de las regiones de origen por lo que podría dañar la eficacia productiva de sus lugares de origen ya sea por su desplazamiento temporal o definitivo, provocando una escasez de fuerza de trabajo en sectores sensiblemente económicos u provocar una disminución del crecimiento y desarrollo.

Este fenómeno tiene incidencia en las personas más jóvenes y con mayor educación o capacitadas laboralmente, ya que emigran para buscar una mejor oportunidad laboral más redituable económicamente, lo cual esta pérdida de mano de obra o de producción, lo que afecta notablemente al desarrollo económico ya que al invertir en educación el estado, se benefician más las comunidades receptoras que las emisoras.

De la incidencia de las modificándoles demográficas regionales tiene una relación directa sobre la mortalidad y la fecundidad, ya que se puede tener una afectación sobre el crecimiento de la población la estructura del sexo, edades poblacionales ya que la migración se da más frecuentemente sobre la gente joven en edad productiva y reproductivas, quedando en las regiones de destino las personas mayores, es decir de las de más edad, aumentando los nacimientos en las regiones de destino, dando como consecuencia una modificación en el crecimiento natural de la región de origen de los individuos, de los cual se puede constatar 


\section{http://revistainvestigacionacademicasinfrontera.com}

que existen en México donde hay entidades federativas como zacatecas, Michoacán y Guanajuato donde se tiene crecimiento casi nulo o negativo en casos extremos.

Otra consecuencia es la demográfica donde las regiones de cual cuenta con más migración existe una desequilibrio de volumen de sexo ya que es más común que emigren varones que mujeres, pero no es una regla determinante ya que pueden darse regiones que sea la migración a los contrario por lo que podría existir modificaciones en el núcleo familiar, social y de genero donde puede darse comunidades donde no exista mano de obra masculina, y que se tenga que tener mayor participación de madres esposas e hijas en al ámbito laboral y productivo lo cual tiene incidencia directa sobre la organización de núcleo familiar

Trayendo como consecuencia modificaciones en la estructura y tamaño de las familias reduciendo significativamente el número de miembros de quienes la conforman, modificando las reglas de derechos y obligaciones familiares.

Se da el caso de poblaciones de México es común la partida del hombre y la esposa tenga que reintegrarse a la familia de sus padres o suegros, y casos donde la esposa permanece en el hogar a cargo de sus hijos y asume la responsabilidad de la casa.

Otro caso es cuando ambos padres han emigrado dejando a cargo de sus hijos a los abuelos ya sea paternos o maternos o con familiares cercanos como tíos o hermanos mayores provocando unos cambios significativos en la composición familiar.

La OIT (Estimaciones mundiales de la OIT sobre los trabajadores y trabajadoras migrantes, 2013) estima que hay 150 millones de trabajadores migrantes, mujeres y hombres

Según estimaciones recientes de la OIT, a nivel mundial hay 150,3 millones de trabajadores migrantes, 11,5 millones de los cuales son trabajadoras y trabajadores domésticos. 


\section{http://revistainvestigacionacademicasinfrontera.com}

Los términos "trabajador migrante" y "trabajadora migrante" designan a todos los y las migrantes internacionales que tienen empleo o que están desempleados y buscan trabajo en el país en que residen.

Los datos sobre trabajadores migrantes utilizados para calcular las estimaciones se refieren a los trabajadores migrantes de uno y otro sexo existentes en el país de destino, y la medición de la población de migrantes corresponde a 2013.

La tasa de participación laboral de los migrantes, en especial la de las mujeres de este grupo, es mayor que la de los no migrantes Los migrantes representan el 3,9 por ciento de la población mundial total (de 15 años de edad o mayores). Sin embargo, la proporción de trabajadores migrantes en el total de trabajadores es mayor (4,4 por ciento). Ello indica una tasa de participación laboral más elevada entre los migrantes $(72,7$ por ciento), frente a la de no migrantes (63,9 por ciento). Esta diferencia está asociada al hecho que hay más mujeres migrantes que trabajan, que mujeres

no migrantes que trabajan (67,0 por ciento frente al 50,8 por ciento), mientras que, en el caso de los hombres, la diferencia entre la tasa de participación laboral entre migrantes y no migrantes es casi inexistente ( 78,0 por ciento frente al 77,2 por ciento).

La migración laboral es un fenómeno que incumbe a todas las regiones del mundo

Casi la mitad de los trabajadores migrantes (el 48,5 por ciento) se concentra en dos amplias subregiones, América del Norte, y Europa meridional, septentrional y occidental.

El 52,9 por ciento de todas las trabajadoras migrantes y el 45.1 por ciento de todos los trabajadores migrantes de sexo masculino se encuentran en estas dos subregiones. 


\section{http://revistainvestigacionacademicasinfrontera.com}

Por el contrario, en los Estados Árabes la diferencia entre los sexos es la opuesta. Esta región concentra el 11,7 por ciento del total de trabajadores migrantes, sinembargo representa el 17,9 por ciento del total de trabajadores migrantes de sexo masculino, y solo el 4,0 por ciento del total de trabajadoras migrantes.

A estas regiones les siguen Europa oriental (9,2 por ciento) y Asia sudoriental y el Pacífico (7,8 por ciento).

Al analizar cada subregión de forma individual, la mayor proporción de trabajadores migrantes como porcentaje del total de trabajadores, el 35,6 por ciento, corresponde a los Estados Árabes. Esa proporción es del 20,2 por ciento en América del Norte y del 16,4 por ciento en Europa septentrional, meridional y occidental, seguidas de Asia central y occidental (10,0 por ciento) y Europa oriental (9,2 por ciento). En cambio, en otras subregiones, la proporción de trabajadores migrantes es inferior al 2 por ciento. La proporción más baja, 0,6 por ciento, está en Asia oriental (incluida China), seguida de África del Norte, Asia meridional (incluida la India), y América Latina y el Caribe, todas dentro del rango del 1,0 y el 1,5 por ciento.

La gran mayoría de los trabajadores y las trabajadoras migrantes se encuentra en países de ingresos altos Del total mundial de 150,3 millones de trabajadoresmigrantes, se calcula que 112,3 millones (el 74,7 por ciento) estaban en países pertenecientes a la categoría de ingresos altos; 17,5 millones (el 11,7 por ciento) en países de ingresos medianos altos; 16,9 millones el (11,3 por ciento) en países de ingresos medianos bajos.

La menor cantidad de trabajadores migrantes se registró en los países de ingresos bajos: 3,5 millones (el 2,4 por ciento). 


\section{http://revistainvestigacionacademicasinfrontera.com}

La población trabajadora migrante, se concentra en determinados sectores económicos Los datos indican una concentración de migrantes en sectores económicos concretos, y diferencias notables según el sexo. El grueso de los trabajadores migrantes del mundo, hombres y mujeres, en 2013 se desempeñaba

en el sector de los servicios, 106,8 millones sobre un total de 150,3 millones, o el equivalente al 71,1 por ciento. La concentración en la industria, incluidas las

manufacturas y la construcción, era de 26,7 millones (el 17,8 por ciento) y en la agricultura, de 16,7 millones $(11,1$ por ciento).

El trabajo doméstico atrae a más de 11 millones de trabajadores migrantes de uno y otro sexo En 2010, tras la adopción de su Convenio sobre las trabajadoras y los trabajadores domésticos, 2011, la OIT produjo las primeras estimaciones mundiales y regionales sobre los trabajadores de este sector, de uno y otro sexo. Esas estimaciones no distinguían entre trabajadores domésticos nacionales y migrantes, pero las nuevas estimaciones sí lo hacen.

Según las estimaciones actuales, en el mundo hay 67,1 millones de trabajadoras y trabajadores domésticos, de los que 11,5 millones son migrantes internacionales.

Esta cuantía representa el 17,2 por ciento del total de trabajadores domésticos, y el 7,7 por ciento de todos los trabajadores migrantes del mundo. Dicho de otro modo,

en 2013, de casi cada seis trabajadores domésticos, uno era migrante internacional.

\section{Conclusiones y recomendaciones:}

El fenómeno de la migración siempre ha sido una manifestación del ser humano, con el fin de tener una mejor calidad de vida, en la actualidad la globalización y la gran diversidad de comunicación y facilidad de trasporte ha facilitado que aumente considerablemente el número de movilizaciones de personas y de trasladarse de un lugar a otro. 


\section{http://revistainvestigacionacademicasinfrontera.com}

Esto ha dado nuevas oportunidades a las sociedades que en cierto momento estaba cerradas a abrirse junto con su población iniciándose una relación más fuerte entre migración y desarrollo, por lo que se debe de aprovechar las mejores condiciones económicas y sociales de los lugares tanto de origen como de destino a fin de que con esta movilidad se tengan más posibilidades de los pueblos de origen y también se beneficien los de destino.

Cada nación tiene el derecho de decidir quién puede entraren su territorio, independientemente de las obligaciones que existan en virtud de tratados internacionales, sin embargo, no es impedimento para frenar la migración legal debido a los beneficios que aportan a los países receptores que en diversas medidas se benefician directa $o$ indirectamente.

Así como también en forma recíproca los lugares de origen de los migrantes por lo que el movimiento de divisas y remesas es tangible y muy perceptible por las naciones y regiones.

La migración es un fenómeno en que se obtienen beneficio tanto para el receptor como del ligar de donde es originario el migrante diversos países el migrante ha contribuido a beneficiar y reforzar sus economías ya que su mayoría están en el trabajo primario principalmente en la producción, manufactura y construcción.

\section{Recomendaciones}

La migración y sus paradigmas han tenido una constante evolución de acuerdo al mercado y economías globalizadas y aunado a las tecnologías ya no existe un rompimiento permanente de las familias y sus comunidades de origen como ocurría en tiempos pasados, considerándose que hay aproximadamente 200 millones de migrantes en el mundo también no se realizan trabajos menores sino también trabajo de alta especialidad. 


\section{http://revistainvestigacionacademicasinfrontera.com}

Como una consecuencia en la modernización de las comunicaciones y trasportes existe una mayor interrelación humana entre las culturas economías y sociedades, en tendiéndose que las riquezas de un país no se van a medir con dinero sino también por los conocimientos técnicas que se acumulen y desarrollen, así como el nuevo conocimiento que se genere por el compartir experiencias aunado con el buen aprovechamiento de la tecnología dando como consecuencia un impacto positivo en el desarrollo económico de las regiones y países.

Se deben implementar políticas publicas afín de aprovechar este nuevo fenómeno y capitalizarlos, diversos organismos internacionales han realizado estudios y coinciden que las naciones deben de enfocar de que las migraciones de personas contribuyan eficientemente al desarrollo económico de las naciones una reformulación de políticas migratorias de las cuales brinden más beneficios a las naciones

\section{Referencias Bibliográficas}

Borisovna Biriukova , L. (2002). Vivir un Espacio, Movilidad, Geografica de la población, . Puebla, Puebla: Instituto de Ciencias Sociales y Humanidades de la BUAP.

Ruiz Garcia, A. (17 de Septiembre de 2002). Coordinación Estatal de Atención al Migrante Oaxaqueñ. Obtenido de Coordinación Estatal de Atención al Migrante Oaxaqueñ: http://www.worldcat.org/title/migracion-oaxaquena-una-aproximacion-a-larealidad/oclc/51327834

Abu-Warda, N. (4 de Octubre de 2008). Revistas Científicas Complutenses. Obtenido de Revistas Científicas Complutenses: http://revistas.ucm.es/index.php/ILUR/article/viewFile/ILUR0707550033A/25848

Alonso, A., \& Otero, L. (15 de julio de 2016). Grandes migraciones de la historia. Hacia la tierra prometida. Obtenido de http://www.muyhistoria.es/contemporanea/articulo/grandesmigraciones-de-la-historia-hacia-la-tierra-prometida

Diccionario demografico multilingüe. (27 de Abril de 2017). Diccionario demografico multilingüe. Obtenido de Diccionario demografico multilingüe: http://www.demopaedia.org/tools/spip.php?page=generate_dictionary\&edition=esii\&format $=\mathrm{html}$ 
Núm. 26

ISSN: 2007-8870

\section{http://revistainvestigacionacademicasinfrontera.com}

Estimaciones mundiales de la OIT sobre los trabajadores y trabajadoras migrantes. (23 de Abril de 2013). Obtenido de Estimaciones mundiales de la OIT sobre los trabajadores y trabajadoras migrantes: http://ilo.org/wcmsp5/groups/public/---dgreports/--dcomm/documents/publication/wcms_436339.pdf

González, D. (12 de Octubre de 2014). cepal.org noticias. Obtenido de cepal.org noticias: http://www.cepal.org/celade/noticias/paginas/5/45125/DGonzalez.pdf

GOZÁLVEZ PÉREZ, V. (1 de Septiembre de 2000). Nueva Revista. Obtenido de Nueva Revista: http://www.nuevarevista.net/articulos/inmigracion-causas-y-perspectivas

Micolta León, A. (2005). Teorías y conceptos asociados al estudio de las. Revista del Departamento de Trabajo Social, 64. 